\title{
Effect of shelf-life simulation on the bond strength of self-etch adhesive systems to dentin
}

\author{
Sueli A Cardoso ${ }^{1}$, Hellen L Oliveira ${ }^{2}$, Eliseu A Mnchow ${ }^{2}$, Neftali LV Carreo ${ }^{3}$, Alcides Gonini Junior ${ }^{4}$ \\ and Evandro Piva ${ }^{5 *}$
}

\author{
* Correspondence: \\ evpiva@gmail.com \\ ${ }^{5}$ Department of Operative Dentistry, \\ School of Dentistry, Federal University \\ of Pelotas, (Rua Gonalves Chaves, \\ 457), Pelotas, RS (96015-560), Brazil \\ Full list of author information is \\ available at the end of the article
}

\begin{abstract}
Self-etch adhesive systems are composed of various monomers, solvents, fillers, and initiators that make their molecular formulations quite complex. The intricate design involved in these systems has raised uncertainties regarding the long-term chemical stability of the components prior to clinical application. Therefore, this study aimed to investigate the effect of shelf-life simulation on the bond strength of self-etch adhesives to dentin. Sound human teeth samples were used and restored using one of three different adhesives: AdheSE (Ivoclar Vivadent), Single Bond Universal (3 M ESPE), or Clearfil SE Bond (Kuraray); Filtek Z350 (3 M ESPE) was used as composite resin. The study (bond strength testing) was conducted in two distinct parts: (1) without shelf-life simulation of adhesives; and (2) after storing the adhesives in a climate chamber at $40 \mathrm{C}$ and $50 \%$ relative humidity (shelf-life simulation). Both groups were prepared for microtensile bond strength ( $\mu \mathrm{TBS}$ ) testing; however, specimens from the first part of the study were evaluated after $24 \mathrm{~h}$ and 6 months of storage in distilled water, whereas specimens from the second part of the study were prepared and tested after 1,2, and 3 months of shelf-life simulation of adhesives. The hybrid layer and fracture pattern of specimens were analyzed by scanning electron microscopy (SEM). Bond strength data were analyzed using Kruskal-Wallis test and Tukey s test ( $a=5 \%)$. When no shelf-life simulation was applied, Single Bond Universal increased bond strength after long-term water storage, whereas AdheSE and Clearfil SE Bond reduced bond strength to dentin. However, the bonding ability of all three adhesive systems investigated was negatively influenced by the shelf-life simulation used.
\end{abstract}

Keywords: Adhesives; Dentin bonding agents; Drug stability; Product storage; Storage of substances; Tensile bond strength

\section{Background}

The development of self-etch adhesive systems in dentistry allowed the bonding protocol to become simpler with faster clinical application [1-5]. Self-etch adhesives are commonly comprised of methacrylate monomers (mono- or bi-functional), solvents, and initiators [6]. Water is also present since it is essential to the ionization of acidic monomers, thus enabling substrate demineralization and subsequent monomer infiltration processes [3,7]. In theory, self-etch adhesives reduce the presence of noninfiltrated collagen layers when compared to etch-and-rinse adhesives since the former can simultaneously demineralize and infiltrate the substrate [8,9]. In addition, the ionization of acidic monomers allows calcium ion chelation and collagen fiber hybridization, which are important adhesion mechanisms in dental bonding [3].

2014 Cardoso et al.; licensee Springer. This is an Open Access article distributed under the terms of the Creative Commons Attribution License (http://creativecommons.org/licenses/by/4.0), which permits unrestricted use, distribution, and reproduction in any medium, provided the original work is properly credited. 
Adhesion to tooth substrates should be stable over time since the success of the restorative procedure depends on this outcome. However, polymerization stresses originating from the volumetric shrinkage of resin composites and hydrolysis of the hybrid layer/adhesive material are considered the most frequent reasons for bonding failure [1,10-12]. Indeed, the latter reason is an important factor responsible for failure of restorations [5,13]. Even though the presence of acidic monomers is essential for dental bonding purposes, the acidic nature of self-etch primers/adhesives is also responsible for increasing hydrolysis phenomena [14]. Moreover, hydrophilic monomers commonly present in self-etch formulations such as the 2-hydroxyl methacrylate (HEMA) and the 10-methacryloyloxydecyl dihydrogen phosphate (MDP) may experience hydrolysis prior to their clinical application when still inside the adhesive vial. This may easily occur if environmental conditions such as humidity and temperature are inadequately controlled, leading to phase separation of the adhesive formulation or volatilization of solvents. Consequently, these chemical alterations may lead to a potential loss of bonding ability of the adhesive [15].

Prior to clinical use, adhesive formulations are designed to maximize chemical stability against premature and accidental polymerization during storage. Additionally, in their pre-packaged condition, adhesives are also designed to resist degradation by oxygen, heat, light, and humidity. Most manufacturer recommendations regarding the storage conditions of these adhesives are to maintain them between 2 and 25-28C prior to the listed expiration date (commonly 2 years). Nevertheless, the shipment, transport, and storage conditions of the adhesives prior to clinical application are not always ideal. This clinical reality may negatively influence the final quality and properties of the material, but it has been rarely investigated in dental biomaterials literature. Therefore, it is of clinical relevance to evaluate the effect of adverse storage conditions on the bonding ability of self-etch adhesive systems.

The aim of this study was to investigate the immediate $(24 \mathrm{~h})$ and long-term (6 months) bond strength of self-etch adhesive systems to dentin, and in addition, to evaluate the effect of shelf-life simulation (storage cycle in climate chamber at $40 \mathrm{C}$ and $50 \%$ relative humidity) on the long-term dentin bond strength of self-etch adhesives. The hypothesis tested was that the shelf-life simulation of vials containing self-etch adhesive formulations would not affect their bonding ability to dentin.

\section{Methods}

\section{Study design and sample s preparation}

Sixty freshly-extracted, sound human molars were selected following approval by the local Institutional Review Board Committee of the University of North Paran (protocol No. 177.305) and cleaned and stored in $0.5 \%$ aqueous solution of chloramine $\mathrm{T}$ for seven days. Next, the roots were removed and each crown was stored in distilled water at 4C until their use, according to ISO TS11405:2003 [16].

The study was designed in two distinct phases: (1) the bond strength test was performed using the traditional environmental settings and protocol used in other studies (i.e., testing the specimens immediately/24 h or after 6 months of water storage); and (2) the bond strength test was performed after shelf-life simulation of the adhesives investigated, i.e. storage in a climate chamber (MA 835/UR, Marconi, Piracicaba, SP, Brazil) at $40 \mathrm{C}$ and $50 \%$ relative humidity for different periods of time $(4,8$, and 
12 weeks). The adhesive system sample groups were the same for all tests: AdheSE (Ivoclar Vivadent, Barueri, SP, Brazil); Single Bond Universal (3 M ESPE, St. Paul, MN, USA); and Clearfil SE Bond (Kuraray, Tokyo, Japan). The design scheme of the study is presented in Figure 1, and the adhesive characteristics (composition, $\mathrm{pH}$, characteristics, lot number, and instructions for application) are shown in Table 1.

\section{Bonding procedures and microtensile bond strength ( $\mu$ TBS) test}

Each tooth had its occlusal enamel removed using decreasing grit-sizes of silica papers in a polishing machine (Aropol-E, Arotec, Rio de Janeiro, RJ, Brazil) until exposure of the middle dentin area. All adhesive systems were then applied by the same operator and following the manufacturers directions of use (Table 2). Each adhesive was then light-activated using a halogen light-curing unit (VIP Junior, Bisco Inc., Schaumburg, IL, USA) with approximately $600 \mathrm{~mW} / \mathrm{cm}^{2}$ of energy intensity utilizing the incremental technique: two 2-mm-thick resin composite increments added in each tooth sample and light-activated for $40 \mathrm{~s}$ each. All samples were then stored in distilled water for $24 \mathrm{~h}$ at $37 \mathrm{C}$, except the long-term specimens of the first phase of the study, which were stored for 6 months (Figure 1).

Next, all samples were sectioned in two perpendicular directions to the bonded interface using a water-cooled diamond saw at low speed (Isomet 1000, Buheler Ltd, Lake Bluff, IL, USA) to obtain beam-shaped specimens with approximately $1.0(0.1) \mathrm{mm}^{2}$ of transverse-sectional area [17]. After $24 \mathrm{~h}$ of water storage, the specimens were submitted to $\mu$ TBS test using a universal testing machine (DL 2000, Emic, So Jos dos Pinhais, PR, Brazil) at a crosshead speed of $0.5 \mathrm{~mm} / \mathrm{min}$. Bond strength results were calculated and expressed in MPa.

\section{Failure mode analysis}

All surfaces were examined using light microscopy available in a microhardness tester (Futuretech FM 700, Tokyo, Japan) at 500 magnification to identify the failure mode

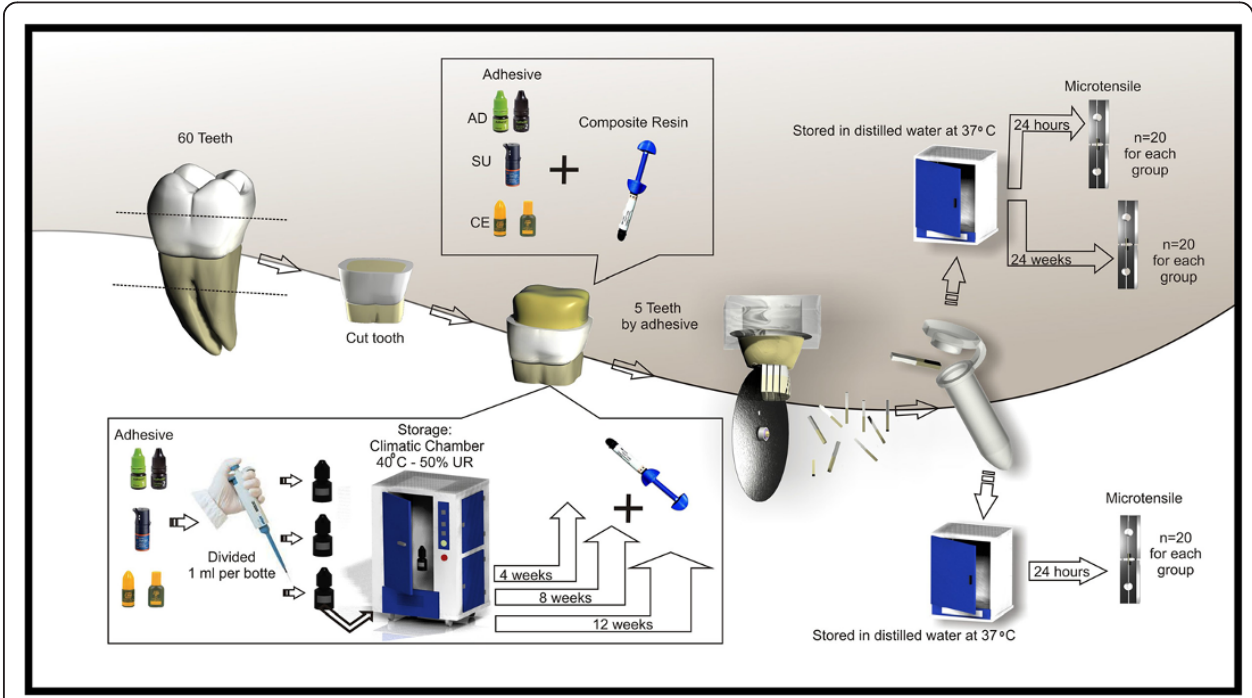

Figure 1 Study design including sample preparation and allocation of groups. 
Table 1 Adhesive systems investigated in the study and information regarding their manufacturers, composition, $\mathrm{pH}$, characteristics, lot number, and instructions of application

\begin{tabular}{|c|c|c|c|}
\hline $\begin{array}{l}\text { Adhesive system/ } \\
\text { (Manufacturer) }\end{array}$ & $\begin{array}{l}\text { Composition/pH } \\
\text { (informed by the } \\
\text { manufacturer) }\end{array}$ & $\begin{array}{l}\text { Characteristics/ } \\
\text { (Lot number) }\end{array}$ & $\begin{array}{l}\text { Instructions of } \\
\text { application* }\end{array}$ \\
\hline $\begin{array}{l}\text { AdheSE } \\
\text { (Ivoclar Vivadent) }\end{array}$ & $\begin{array}{l}\text { Primer: aqueous solution of } \\
\text { dimethacrylate, acrylate } \\
\text { phosphonic acid, initiators, } \\
\text { and stabilizers ( } \mathrm{pH}=1.7) \text { Bond: } \\
\text { HEMA, dimethacrylate, silica, } \\
\text { initiators, and stabilizers }\end{array}$ & 2-steps (R07816) & $\begin{array}{l}\text { a (15 s); a (15 s); } \\
\text { b; c; d; e (10 s) }\end{array}$ \\
\hline $\begin{array}{l}\text { Single Bond Universal } \\
\text { (3M ESPE) }\end{array}$ & $\begin{array}{l}\text { Bis-GMA, MDP, dimethacrylate } \\
\text { resins, HEMA, Vitrebond } \\
\text { copolymer, water, photoinitiator } \\
\text { (CQ) }(\mathrm{pH}=2.7)\end{array}$ & 1-step (1305900374) & $\begin{array}{l}f(20 \mathrm{~s}) ; d(5 s) \\
e(10 s)\end{array}$ \\
\hline $\begin{array}{l}\text { Clearfil SE Bond } \\
\text { (Kuraray) }\end{array}$ & $\begin{array}{l}\text { Primer: MDP, HEMA, dimethacrylate } \\
\text { monomer, N,N-diethanol-p-toluidine, } \\
\text { microfillers (silanized colloidal silica), } \\
\text { photoinitiator (CQ) (pH = 2.0) Bond: } \\
\text { HEMA, Bis-GMA, dimethacrylate } \\
\text { monomer, N,N-diethanol-p-toluidine, } \\
\text { microfillers (silanized colloidal silica), } \\
\text { photoinitiator (CQ) }\end{array}$ & 2-steps (051506) & $\begin{array}{l}\text { a }(20 \mathrm{~s}) ; \mathrm{d} ; \mathrm{c} ; \mathrm{d} ; \\
\text { e }(10 \mathrm{~s})\end{array}$ \\
\hline
\end{tabular}

HEMA: 2-hydroxyethyl methacrylate; Bis-GMA: 2,2-bis[4-(2-hydroxy-3-methacryloyloxypropyl)phenyl]-propane; MDP: 10methacryloyloxydecyl dihydrogen phosphate; $\mathrm{CQ}$ : camphorquinone.

*a: primer application; b: drying with strong air-spray; c: bond application; drying with slight air-spray; e: light-activation;

f: adhesive application.

patterns obtained. The patterns were classified as adhesive (at the interface between tooth/restoration), cohesive in dentin (exclusively at the dentin substrate), cohesive in composite resin (exclusively at the restoration), or mixed (when the failure occurred at the adhesive interface and at least one more pattern).

\section{Scanning electron microscopy (SEM) analysis}

One sample of each adhesive system was prepared for SEM evaluation of the hybrid layer formed. Samples were then polished with \#600-, \#1200-, \#1500-, \#2000-, and \#2500-grit silica papers for 15 minutes each, followed by polishing with felt disc using diamond suspensions of 3, 1, and $0.25 \mu \mathrm{m}$ (MetaDi, Buheler) for 10 minutes each. Next, samples were washed with distilled water and etched with $50 \%$ phosphoric acid solution during $5 \mathrm{~s}$, washed again for $30 \mathrm{~s}$ and then immersed in 2.5\% sodium hypochlorite solution for 10 minutes. The samples were cleaned in ultrasound, stored dry for $24 \mathrm{~h}$,

Table 2 Microtensile bond strength median values (in $\mathrm{MPa}$ ) and pooled average of adhesive systems investigated in the study after immediate (24 h) and long-term (6 months) water storage, with no shelf-life simulation of adhesives

\begin{tabular}{llll}
\hline Adhesive systems & \multicolumn{2}{l}{ Time of evaluation } & Pooled average* \\
\cline { 2 - 4 } & $\mathbf{2 4} \mathbf{~}$ & $\mathbf{6}$ months & $24.1 \mathrm{~b}$ \\
\hline AdheSE & 46.2 & 13.1 & $63.3 \mathrm{a}$ \\
Single Bond Universal & 49.1 & 83.0 & $64.2 \mathrm{a}$ \\
\hline
\end{tabular}

*Distinct superscript letters after pooled average medians indicate statistically significant differences among the adhesives evaluated $(p<0.05)$. 
and then sputter coated with gold. The hybrid layer zone (adhesive interface) was analyzed using a scanning electron microscope (SSX-550, Shimadzu, Tokyo, Japan).

One representative specimen of each failure mode pattern obtained was also evaluated in the scanning electron microscope, where each specimen was only dried and sputter coated with gold.

\section{Statistical analysis}

The bond strength data were analyzed with the statistical program SigmaPlot version 12 (Systat Software Inc., San Jose, CA, USA) using Kruskal-Wallis One Way Analysis of Variance and Tukeys test for multiple comparison $(\alpha=5 \%)$. A linear regression model was used to analyze the correlation between the microtensile bond strength results and the shelf-life period of the adhesive systems.

\section{Results}

The $\mu$ TBS results and failure mode patterns obtained in the study are shown in Figure 2. For AdheSE and Clearfil SE Bond adhesives, shelf-life simulation for 8 and 12 weeks demonstrated similar median bond strength values when compared to 6 months of water storage, which were significantly less than the $\mu$ TBS median values obtained for the baseline $(24 \mathrm{~h})$ and 4-week shelf-life simulation groups (Figure 2A and C). While mixed failure mode was the most frequent within AdheSE, both mixed and cohesive in resin composite failure patterns occurred $n$ equal frequency for Clearfil SE Bond (Figure 2D and F). For Single Bond Universal, shelf-life simulation for 4 weeks and water storage for 6 months resulted in higher bond strength median values than the baseline and 8- or 12-week groups (Figure 2B). Cohesive failures at the composite resin were the most frequent pattern obtained (Figure 2E).

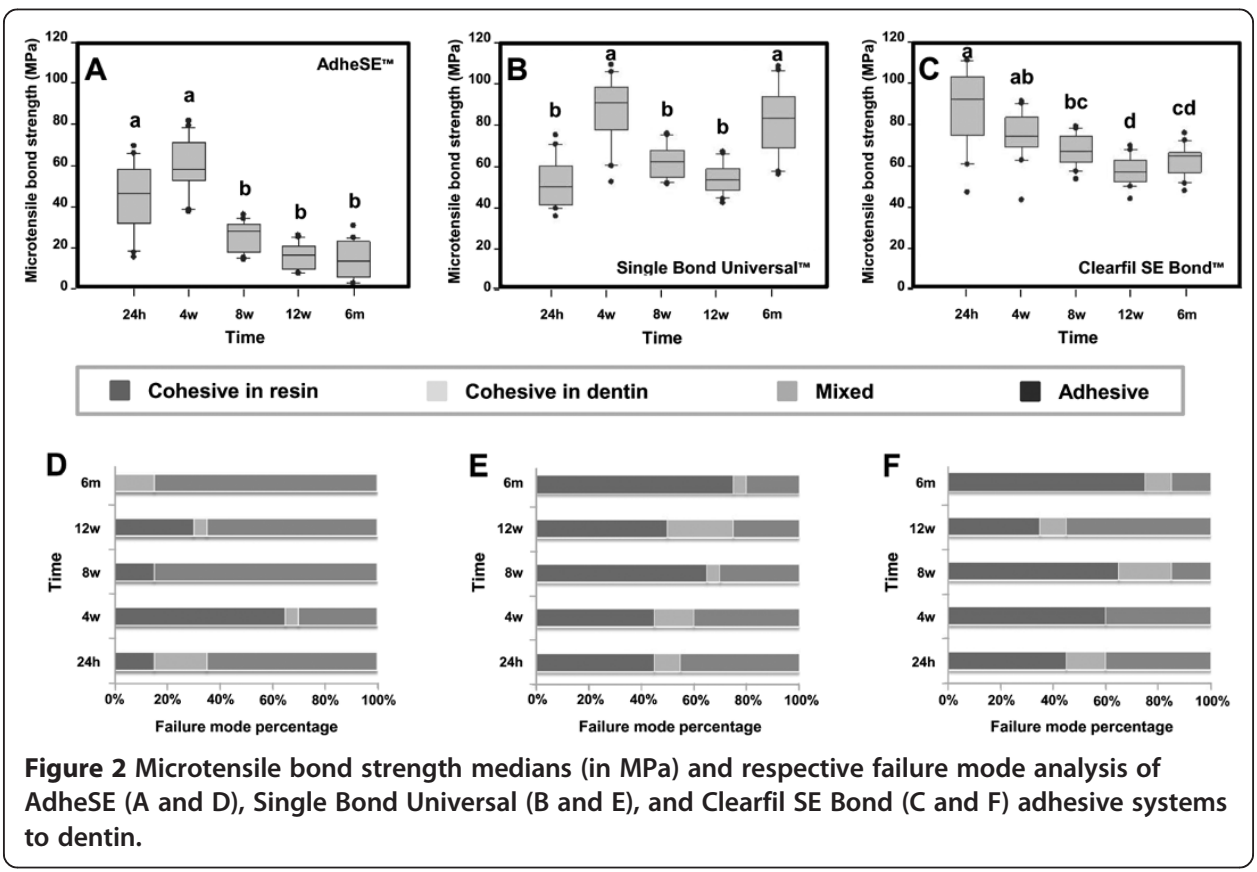


A positive correlation between $\mu \mathrm{TBS}$ median according to time of shelf-life simulation was obtained only for Clearfil SE Bond, which demonstrated an excellent adjust to the linear regression model used, as shown in Figure $3\left(R^{2}>0.98 ; p<0.01\right)$.

With regard to the bond strength ability of the different adhesive systems, Single Bond Universal and Clearfil SE Bond showed comparable $\mu$ TBS median values, which were higher than AdheSE (Table 2).

SEM images obtained in the study are presented in Figure 4. AdheSE resulted in longer resin tags (images A and B), while Single Bond Universal (images $C$ and D) and Clearfil SE Bond (images $\mathrm{E}$ and F) produced, respectively, intermediate and short resin tags. Furthermore, AdheSE, Single Bond Universal, and Clearfil SE Bond showed an adhesive layer thickness of 7.5, 13.3, and $11.1 \mu \mathrm{m}$, respectively.

\section{Discussion}

The self-etch adhesives investigated in the present study can be categorized with regard to their $\mathrm{pH}$ as: intermediately strong (AdheSE), mild (Clearfil SE Bond), and ultramild (Single Bond Universal) adhesives [18]. This difference in acidity allowed an interesting evaluation of their aggressiveness, influence on tooth demineralization, and photo-polymerization performance [19].

According to Figure 4, AdheSE, which had the most acidic $\mathrm{pH}$ of the samples in this study, demonstrated higher monomer infiltration (resin tags) and lower hybrid layer thickness when compared to the other adhesives (Figure 4A,B). This relationship between the quality of monomer infiltration and low $\mathrm{pH}$ of adhesives is consistent with previous studies [20-22]. Nevertheless, Clearfil SE Bond showed lower tags extension than Single Bond Universal, although it had a more acidic $\mathrm{pH}$ than the latter (Figure 4C-F). In addition to the $\mathrm{pH}$ of the adhesive, another important factor in the quality of the hybrid layer formed by using mild and ultra-mild self-etch adhesives is the nature of the acid-functional monomer. Some monomers, such as MDP, are able to chemically interact with tooth minerals, thus improving the micro-mechanical bond strength of the bonding process $[21,23]$.

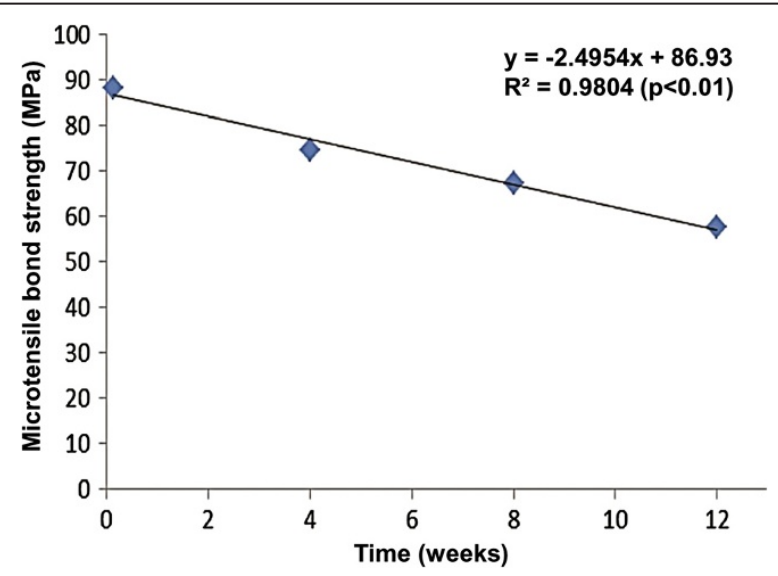

Figure 3 Linear regression model showing the relationship between the microtensile bond strength median values obtained with Clearfil SE Bond after different periods of shelf-life simulation. 

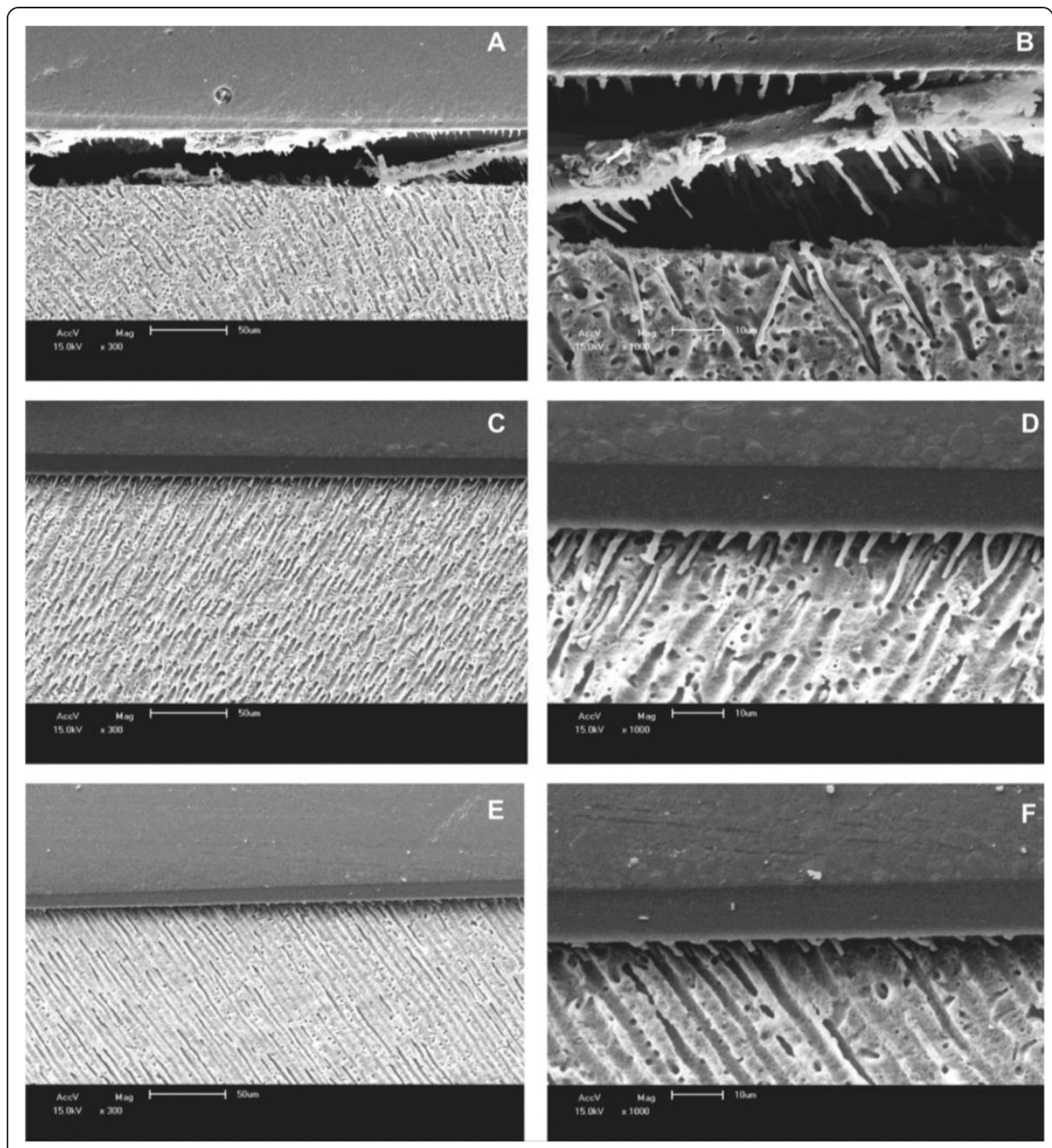

Figure 4 Scanning electron microscopy images showing the adhesive interface obtained after application of AdheSE (A and B), Single Bond Universal (C and D), and Clearfil SE Bond (E and F).

Besides the importance of the acidity [24] of adhesives and their water content [3] for ionization and demineralization purposes, surfactant monomers have been recently used in adhesive formulation in an attempt to control resin monomer infiltration [25]. This factor may explain the hybridization mode of Single Bond Universal, which may apply surfactant technology that was previously noted in a patent from the $3 \mathrm{M}$ ESPE Corporation [26]. However, qualitative SEM surveys alone are not enough to demonstrate an effective and stable adhesion to dental substrates [22]. As a consequence, mechanical bond strength testing was also evaluated in the study.

Interestingly, Single Bond Universal, which produced a satisfactory hybrid layer as seen in Figure $4(C, D)$, increased the bond strength values after shelf-life simulation for 4 weeks or even after 6 months of water storage (Figure 2). In contrast, AdheSE and Clearfil SE Bond resulted in significant bond strength reduction after the different periods of shelflife simulation and also after the 6-month water storage, suggesting the occurrence of a hydrolytic phenomenon [13]. Considering these results, the experimental hypothesis that 
shelf-life simulation of self-etch adhesives would not affect their bonding ability to dentin can be rejected.

Single Bond Universal has a unique formulation different from other adhesives. In this adhesive system, the presence of the Vitrebond copolymer, which is known to promote higher stability against humidity deterioration [27], has likely contributed to the higher bond strength values obtained. In addition, the copolymer is able to dissipate stress at the adhesive interface [28] due to its chemical interaction with hydroxyapatite minerals [29]. Moreover, it can be suggested that specific temperature and humidity conditions may induce better monomer reticulation with the copolymer, and considering that 4 weeks of shelf-life simulation showed higher bond strength than 8 - and 12-week periods (Figure 2), this notion can be supported.

MDP is a common acid-functional monomer present in both Single Bond Universal and Clearfil SE Bond. When mixed with HEMA, it is able to improve the wetting ability of dentin, leading to better interaction of the adhesive with hydroxyapatite crystals [30,31] and to lower solubility of crystals [23]. According to Inoue et al. [32], MDP may chemically interact with tooth substrates, increasing the hydrolytic stability of the hybrid layer, which in fact results in long-term bond strength. Nonetheless, Aida et al. [15], have demonstrated strong degradation effects of primers containing MDP and HEMA when stored in temperature conditions of 40C.

Regarding the Clearfil SE Bond adhesive, a proportional decrease in bond strength results were observed with increasing shelf-life period of time (Figures $2 \mathrm{~B}$ and 3 ). This clearly demonstrates the negative effect of adverse temperature and humidity conditions on the storage of adhesive systems. This may explain why the manufacturer recommends keeping this adhesive under refrigeration. For the other adhesives, manufacturers recommend storing AdheSE and Single Bond Universal in temperature conditions ranging from 2-28C and 2-25C, respectively. Indeed, the present findings support these recommendations; otherwise, proportional degradation of the product may occur.

The shelf-life simulation used in the present study is considered an adverse circumstance that is not uncommon during import/export transportation of the product. Fluctuations in temperature and humidity produce significant changes in the chemical stability and physical and mechanical properties. The significant reduction in the bond strength results observed for all three adhesive systems after 12 weeks of shelf-life simulation, when compared to a 4-week period of time, demonstrates that chemical degradation of components may invariably compromise their bonding ability to dentin.

This study investigated the degradation susceptibility of adhesive systems stored in adverse temperature and humidity conditions. While some studies have already evaluated this outcome by storing the products in temperatures ranging from 37 to $42 \mathrm{C}$ $[5,14,15,33]$, the proper control of humidity was primarily obtained in the present study. A 50\% relative humidity was combined with a constant temperature of 40C. The relative humidity condition affects the amount of water present in the environment, which consequently may affect the vapor pressure parameters of the water and solvent contents present into the adhesive composition. Considering that all adhesives investigated were water-based, combined with the fact that Single Bond Universal was also ethanol-based, it can be concluded that solvent volatilization may occur even inside a closed vial. 
Despite the fact that the aging evaluation of dental bonded interfaces is commonly performed by storing specimens in water for different periods of time (as performed in the first phase of the study) [34], the shelf-life simulation of adhesive vials may be also used in an attempt to obtain important information about the degradability of dental adhesives in regards to their bonding ability. Manufacturers usually perform shelf-life simulation as a standard process during the development of new products. Nevertheless, combining both methods (shelf-life simulation and storage of specimens) may be important for predicting the degradation susceptibility of adhesive blends before polymerization, as well as after their application to the tooth substrate.

Further studies evaluating different conditions of temperature and humidity are necessary to clarify the degradation and hydrolytic phenomena that adhesives may suffer. After that, a recommendation for the ideal storage conditions of dental adhesives may be satisfactorily obtained.

\section{Conclusion}

When no shelf-life simulation was applied, Single Bond Universal increased bond strength after long-term water storage, whereas AdheSE and Clearfil SE Bond reduced bond strength to dentin. However, the bonding ability of all three adhesive systems investigated was negatively influenced by the shelf-life simulation used.

Competing interests

The authors declare that they have no competing interests.

\section{Authors contributions}

SAC and HLO participated in performing the experiments and writing of the manuscript. EAM contributed to the writing of the manuscript. NLVC performed the statistical analysis. AGJ and EP conceived the study, participated in its design and coordination, as well as helped with the composition of the manuscript. All the authors have read and approved the final manuscript.

\section{Acknowledgements}

The authors thank Adriana de Oliveira Silva for her assistance with the figures.

\section{Author details}

${ }^{1}$ Graduate Program in Dentistry, School of Dentistry, Norte do Paran University, (Av. Paris, 675), Londrina, PR (86041-120), Brazil. ${ }^{2}$ Graduate Program in Dentistry, School of Dentistry, Federal University of Pelotas, (Rua Gonalves Chaves, 457), Pelotas, RS (96015-560), Brazil. ${ }^{3}$ Developmental and Control Center of Biomaterials, Federal University of Pelotas, (Rua Gonalves Chaves, 457), Pelotas, RS (96015-560), Brazil. ${ }^{4}$ Department of Restorative Dentistry, University of North Paran, (Av. Paris, 675), Londrina, PR (86041-120), Brazil. ${ }^{5}$ Department of Operative Dentistry, School of Dentistry, Federal University of Pelotas, (Rua Gonalves C haves, 457), Pelotas, RS (96015-560), Brazil.

Received: 24 October 2014 Accepted: 3 December 2014

Published online: 24 December 2014

References

1. Aboushelib MN. Clinical performance of self-etching adhesives with saliva contamination. J Adhesive Dent. 2011; 13:489 93.

2. Huhtala MFRL, Silva MA, Barcellos DC, Torres CRG, Pucci CR, Gonalves SEP, Gomes APM. Influence of self-etching adhesive systems on restorative material surface. World J Dent. 2011; 2:93 8.

3. Lima GS, Ogliari FA, Moraes RR, Mattos ES, Silva AF, Carreo NLV, Petzhold CL, Piva E. Water content in self-etching primers affects their aggressiveness and strength of bonding to ground enamel. J Adhes. 2010; 86:939 52.

4. Naughton WT, Latta MA. Bond strength of composite to dentin using self-etching adhesive systems. Quintessence Int. 2005; 36:259 62.

5. Salz U, Zimmermann J, Zeuner F, Moszner N. Hydrolytic stability of self-etching adhesive systems. J Adhesive Dent. 2005: 7:107 16

6. Mnchow EA, de Barros GD, Alves LS, Valente LL, Cava SS, Piva E, Ogliari FA. Effect of elastomeric monomers as polymeric matrix of experimental adhesive systems: degree of conversion and bond strength characterization. Appl Adhesion Sci. 2014; 2:3

7. Hiraishi N, Nishiyama N, Ikemura K, Yau JY, King NM, Tagami J, Pashley DH, Tay FR. Water concentration in self-etching primers affects their aggressiveness and bonding efficacy to dentin. J Dent Res. 2005; 84:653 58.

8. Van Landuyt KL, Kanumilli P, De Munck J, Peumans M, Lambrechts P, Van Meerbeek B. Bond strength of a mild self-etch adhesive with and without prior acid-etching. J Dent. 2006; 34:77 85. 
9. Vaz VTP, Minto AMP, Mandarino F, Thom LHC. Efeito da tcnica de aplicao de trs sistemas adesivos autocondicionantes sobre a ultramorfologia da camada hbrida. Revista Dental Press Esttica. 2011; 8:88 95.

10. Gopferich A. Mechanisms of polymer degradation and erosion. Biomaterials. 1996; 17:103 14.

11. Nikaido T, Kunzelmann KH, Chen H, Ogata M, Harada N, Yamaguchi S, Cox CF, Hickel R, Tagami J. Evaluation of thermal cycling and mechanical loading on bond strength of a self-etching primer system to dentin. Dent Mater. 2002; 18:269 75.

12. Van Landuyt KL, De Munck J, Mine A, Cardoso MV, Peumans M, Van Meerbeek B. Filler debonding \& subhybridlayer failures in self-etch adhesives. J Dent Res. 2010; 89:1045 50.

13. De Munck J, Van Landuyt K, Peumans M, Poitevin A, Lambrechts P, Braem M, Van Meerbeek B. A critical review of the durability of adhesion to tooth tissue: methods and results. J Dent Res. 2005; 84:118 32

14. Salz $U$, Bock T. Adhesion performance of new hydrolytically stable one-component self-etching enamel/dentin adhesives. J Adhesive Dent. 2010; 12:7 10.

15. Aida M, Odaki M, Fujita K, Kitagawa T, Teshima I, Suzuki K, Nishiyama N. Degradation-stage effect of self-etching primer on dentin bond durability. J Dent Res. 2009; 88:443 48.

16. International Organization for standardization: ISO TS11405, Dental materials - Testing of adhesion to tooth structure; 2003.

17. Mnchow EA, Bossardi M, Priebe TC, Valente LL, Zanchi CH, Ogliari FA, Piva E. Microtensile versus microshear bond strength between dental adhesives and the dentin substrate. Int J Adhes Adhes. 2013; 46:95 9.

18. Van Meerbeek B, De Munck J, Yoshida Y, Inoue S, Vargas M, Vijay P, Van Landuyt K, Lambrechts P, Vanherle G. Buonocore memorial lecture. Adhesion to enamel and dentin: current status and future challenges. Oper Dent. 2003; 28:215 35

19. Zhang $Y$, Wang $Y$. Effect of reactive and un-reactive substrates on photopolymerization of self-etching adhesives with different aggressiveness. Dent Mater J. 2013; 32:484 91.

20. Fontes ST, Cubas GBA, Flores JB, Montemezzo ML, Bueno M, Piva E. Stability of ten contemporary etch-and-rinse adhesive systems to resin-dentin bond. Gen Dent. 2010; 58:257 61

21. Koshiro K, Sidhu SK, Inoue S, Ikeda T, Sano H. New concept of resin-dentin interfacial adhesion: the nanointeraction zone. J Biomed Mater Res B Appl Biomater. 2006; 77:401 08.

22. Manhart J, Trumm C. Marginal adaptation of an etch-and-rinse adhesive with a new type of solvent in class II cavities after artificial aging. Clin Oral Investigations. 2010; 14:699 705.

23. Yoshida Y, Nagakane K, Fukuda R, Nakayama Y, Okazaki M, Shintani H, Inoue S, Tagawa Y, Suzuki K, De Munck J, Van Meerbeek B. Comparative study on adhesive performance of functional monomers. J Dent Res. 2004; 83:454 58 .

24. Leal FB, Madruga FC, Prochnow EP, Lima GS, Ogliari FA, Piva E, Moraes RR. Effect of acidic monomer concentration on the dentin bond stability of self-etch adhesives. Int J Adhes Adhes. 2011; 31:571 74

25. Zanchi CH, Munchow EA, Ogliari FA, de Carvalho RV, Chersoni S, Prati C, Demarco FF, Piva E. A new approach in self-etching adhesive formulations: replacing HEMA for surfactant dimethacrylate monomers. $J$ Biomed Mater Res B Appl Biomater. 2011; 99:51 7.

26. Craig BD, Aasen SM, Abuelyaman AS, Hecht R, Luchterhandt T, Rao PS, Shukla BA, Watermann M. Inventors; Self-Etching Dental Compositions and Methods. US patent 7449499. 2008.

27. Fundingsland JW, Bodger PD, Aasen SM. The effect of high humidity on adhesion to dentine. J Dent Res. 1992: 71(1992)665, (Abstract number 1199).

28. Cardoso PE, Placido E, Francci CE, Perdigao J. Microleakage of Class V resin-based composite restorations using five simplified adhesive systems. Am J Dent. 1999; 12:291 94.

29. Yoshida Y, Van Meerbeek B, Nakayama Y, Snauwaert J, Hellemans L, Lambrechts P, Vanherle G, Wakasa K. Evidence of chemical bonding at biomaterial-hard tissue interfaces. J Dent Res. 2000; 79:709 14

30. Moszner N, Salz U, Zimmermann J. Chemical aspects of self-etching enamel-dentin adhesives: a systematic review. Dent Mater. 2005; 21:895 910.

31. Toledano M, Osorio R, de Leonardi G, Rosales-Leal Jl, Ceballos L, Cabrerizo-Vilchez MA. Influence of self-etching primer on the resin adhesion to enamel and dentin. Am J Dent. 2001; 14:205 10.

32. Inoue S, Koshiro K, Yoshida Y, De Munck J, Nagakane K, Suzuki K, Sano H, Van Meerbeek B. Hydrolytic stability of self-etch adhesives bonded to dentin. J Dent Res. 2005; 84:1160 64.

33. Fujita K, Nishiyama N. Degradation of single bottle type self-etching primer effectuated by the primer's storage period. Am J Dent. 2006; 19:111 14.

34. Amaral FL, Colucci V, Palma-Dibb RG, Corona SA. Assessment of in vitro methods used to promote adhesive interface degradation: a critical review. J Esthet Restorative Dent. 2007; 19:340 53. discussion 54.

doi:10.1186/s40563-014-0026-9

Cite this article as: Cardoso et al:: Effect of shelf-life simulation on the bond strength of self-etch adhesive systems to dentin. Applied Adhesion Science 2014 3:26. 